\section{JSIT}

14,1

\section{2}

\title{
Effects of e-mail addiction and interruptions on employees
}

\author{
Laura Marulanda-Carter and Thomas W. Jackson \\ Department of Information Science, Loughborough University, \\ Loughborough, UK
}

\begin{abstract}
Purpose - The purpose of this paper is to explore the effect of e-mail interruptions on tasks and to explore the concept of e-mail addiction within the workplace.

Design/methodology/approach - Data were collected from a large car rental company in the UK. The first collection method involved observing the effects of simulated e-mail interruptions on seven employees by measuring the interrupt handling time, the interrupt recovery time, and the additional time required to complete the task given the number of interruptions. The second part of the study involved a questionnaire sent to 100 employees to capture addictive characteristics in employees' e-mail communication behaviour.

Findings - E-mail interruptions have a negative time impact upon employees and show that both interrupt handling and recovery time exist. A typical task takes one third longer than undertaking a task with no e-mail interruptions. The questionnaire data show clinical characteristics classify 12 per cent of e-mail addicts, and behavioural characteristics classify 15 per cent of e-mail addicts in the workplace.

Research limitations/implications - Observation was constrained by the timeframes and availability of the participating organisation. Measuring an employee receiving e-mail interruptions over a greater time period might achieve a more comprehensive understanding of the impact.

Originality/value - The small study is the first to determine the impact of e-mail interruptions on work tasks by observing employees, and to present a method to determine e-mail addiction. By understanding these factors, organisations can manage workflow strategies to improve employee efficiency and effectiveness.
\end{abstract}

Keywords United Kingdom, Employees behaviour, Electronic mail, Addiction, e-mail addiction, e-mail handing, e-mail recovery time, Managing e-mail communications, Task interruption

Paper type Research paper

\section{Introduction}

Computer mediated communication systems can often create as many problems for an organisation as they solve. The volume and pace of information can become overwhelming, especially since messages are not necessarily sequential and multiple topic threads are common, resulting in amongst other factors, information overload (Hiltz and Turoff, 1985; Kerr and Hiltz, 1982). As defined by Bawden (2001): "Information overload occurs when information received becomes a hindrance rather than a help when the information is potentially useful". It is tempting to assume that the major contributing factor in the workplace is "too much information" (Bawden et al., 1999), and some believe that too much information is likely to be better than not enough (Tjaden, 2007). In an increasingly connected global economy, it is true that we depend on information, in varied media, to stay current and make decisions. However, the growing pressures to consume Technology

Vol. 14 No. 1, 2012

pp. $82-94$

(C) Emerald Group Publishing Limited 1328-7265 more and more information and to work faster and better than ever before has DOI 10.1108/13287261211221146 
self induced (Wojcik, 2005). Hallowell identifies the negative neurological effects of information overload, describing it as Attention Deficit Trait (ADT):

[ADT is] caused by brain overload (Hallowell, 2005). ADT is now epidemic in organisations. The core symptoms are distractibility, inner frenzy, and impatience. People with ADT have difficulty staying organised, setting priorities, and managing time.

Organisations make concerted efforts to introduce all possible means of improving and maintaining high work performance levels, on the assumption that deterioration of individual capabilities at work will damage organisational performance (Mano and Mesch, 2010). Every method of communication has its place but, email has proved itself to be a strong contender in many situations, especially in business (Bawden, 2001). Email allows for a number of organisational benefits, including the ability to create timely information and information permanency, as well as increasing information accuracy and colleague interaction (O'Kane and Hargie, 2007). Email has even been attributed to the success of just-in-time knowledge, and knowledge integration within everyday work practices (Lichtenstein and Swatman, 2003; Fallows, 2002). It is the capability to quickly and easily distribute a message with an attachment such as documents, links, objects, etc. - to a large dispersed audience, with tracking and audit, which cannot be matched by any other communication technology to date (Anthes, 2006; Brown, 2007) and is vital to accessibility, quantity, and quality of information.

Empirical data shows that although email was originally designed as a communications application it is now being used for additional functions that it was not designed for, such as task management and personal archiving (Whittaker and Sidner, 1996; Rennie, 2000). Some individuals experience major problems in reading and replying to email in a timely manner, and suffer from back logs of unanswered email and finding information (Whittaker and Sidner, 1996). The challenge in the workplace is that managing email is now a standard requirement and principal part of worker's day-to-day tasks (Brown, 2007). Email increases the number of tasks that employees perform and, as a consequence, their level of control over those tasks. As stated by Zelikovich (2011) not only does email require more attention, subsequently causing larger costs, it also in some cases implicitly imposes administration costs on employees because of the need to handle so much more information. Studies now suggest that email may be hindering rather than helping workplace performance (Mano and Mesch, 2010).

Burgess et al. (2005) recognised that email interruptions could be causing some of these email problems, where interruptions lead to time inefficiencies and employees become distracted and forced to stop their planned work. Furthermore, Stafford suggests that the volume of email has led to some users to become addicted to email (Hair et al., 2007). He suggests that the fundamental learning mechanisms that drive gambling addicts can be associated with email users, suggesting that the variable interval reinforcement schedule is in play. Thus, rather than reward an action every time it is performed, it is rewarded only sometimes. Stafford advocates that this is enough to make it difficult for users to resist checking email. Consequently, problems of email use have become more inherent among users. A ClearContext survey found that 56 per cent of people spent more than two hours a day in their inbox, and 38 per cent of respondents received more than 100 emails a day (Anderson, 2011). Hair et al. (2007) found that 34 per cent of information workers felt stressed by the volume of emails,
Effects of e-mail addiction 
JSIT 14,1

\section{4}

50 per cent checked their email every hour and 35 per cent checked their email every 15 minutes. They identified one in three workers as suffering from email stress.

This paper builds on Jackson et al.'s (2002) research surrounding interrupt recovery time and investigates the association of email interruptions and work performance, in particular identifying occurrence, handling, additional time taken to complete a task, interrupt read and response times, and recovery time of email interruptions. It also identifies the characteristics that classify an email addict from both clinical and behavioural perspectives. The paper starts by looking at the research into the effects on task interruption and email employee behaviour. It then outlines the methods used to look at both the effects of email interrupts and the measuring of email addiction. The results and discussion form the next section of the paper and it finishes with a conclusion and limitations of the research.

\section{The known effects of task interruption and email addiction}

Back in 2002, Jackson, Dawson and Wilson evaluated the effect of email interruptions within the workplace (Jackson et al., 2002). Similarly to Solingen et al. (1998) they compared email to another medium of interrupt, the telephone. Solingen et al. (1998) claim that interruptions have three phases: occurrence, handling and recovery. More concisely an interruption can be defined as "any distraction that makes a [person] stop their planned activity to respond to the interrupt's initiator". In comparing the two, Jackson et al. (2002) found that 70 per cent of emails dealt with were viewed within six seconds, which was faster than letting the telephone ring three times. Czerwinski et al. (2004) adopted diary studies as a method of analysing the effect of interruptions in information workers. Furthermore, she found that email took up 23 per cent of the users' day, and it was found to be the most popular task and a common cause for task switching.

However, the interesting discovery in Jackson's work is that instead of delaying the response time which is more convenient to the user, the user reacted almost instantly within six seconds. In addition, they suggest by example, that if it takes on average one and a half minutes to read and recover from an email and the employee is interrupted every five minutes, then an employee could have up to 96 interruptions in a normal eight hour working day. Jackson et al. also identified that the recovery time from an email interruption is 64 seconds; this is also significantly less than published recovery times of a telephone call, which is 15 minutes (DeMarco and Lister, 1999). This research detailed in this paper proposed a new set of questions regarding how people manage email interrupts and the effect it has on their work. Jackson et al. identifies the issue but does not develop discussion on an individual's perspective of work, email, or consider the culture that surrounds the urgency of dealing with emails straightaway and invoking multitasking, as opposed to waiting until one has finished their original task.

What is unclear from the research to date is the effect of email multitasking on employees. Whilst multitasking is shorthand for the human attempt to do simultaneously as many things as possible and as quickly as possible (Rosen, 2008), how the human brain deals with memory and thought processes is crucial in understanding the motions of human behaviour and its interaction with technology. Zull (2002) developed memory as a situation of time:

[...] part of having a good memory is to recall things long after they happened but there is also value in remembering things for only a short time and forgetting after solving the problem. 
It has been argued that we process items intently in working memory for up to 45 minutes before becoming fatigued (Sternberg, 2006). In contrast, Russell (1979) suggests the short-term memory time span in adults varies between ten and 20 minutes. The short-term memory temporarily stores information, but how do we forget information in short-term memory. Several theories have been proposed as to why we forget information, the most well known is the interference theory and decay theory. According to the interference theory the recall of certain words interferes with the recall of other words. Conversely, the decay theory asserts that information is forgotten because of the gradual disappearance, rather than displacement of the memory trace (Sternberg, 2006). On the contrary, it is argued that information is processed one chunk after another. Parallel processing asserts that the brain seems to handle many operations and processes information from many sources simultaneously. This theory is supported by the fact that humans can in fact multitask.

Multitasking is now expected, if not presumed normal, for workplace employees. Before technology was incorporated in workplace activities, theorists (Meyer et al., 1997; Kieras et al., 2000; Lauber, 1995) identified the costs of multitasking when the brain actively attempts to deal with task switching. In their paper Meyer et al. (1997) found that slower responses occurred during task switching in comparison to repeated performance of a single task. When considering all the data of early experiments into task switching, laboratory settings are used and found to be most congenial. The everyday or real world approach calls for more correspondence to engage the "whole host of executive mental processes that people presumably have" (Sternberg, 2006; Kieras et al., 2000). Whilst studies show email interruptions within the workplace lead to poor time management and less efficiency in employees (Burgess et al., 2005), this study is concerned with the additional time required to complete a workplace task after being interrupted by email. Even though the principle of email management has been cause for concern since email was created, the effect of email on human behaviour has only recently been recognised as an urgent call for concern.

The literature indicates there is a problem with email communication in the workplace. Whilst employees are expected to manage their daily tasks, email interruptions promote a new way of dealing with information. First, in terms of time lost recovering from email interruptions, and second in terms of behaviour. Building on the research into responding to email and interrupt recovery times, this research studies the effect of five minute email interruptions on employees in the workplace, and tests the seven year old research findings of Jackson et al. (2003):

H1. Simulated five minute email interruptions will cause an interrupt handling time of around 1.5 minutes and a recovery time of around 64 seconds.

The second part of the research involves determining the behavioural aspects of dealing with email.

In recent years there has been limited research into the correlation between the fundamental learning mechanisms that drive addicts and email users. In conjunction with Beta Research, AOL conducted an independent online survey in 2008 of 4,000 email users in the top-20 US markets. Almost half, 46 per cent, of email users claim to be addicted to email (Begun, 2008). This concept is now commonly referred to as "email addiction" (Anderson, 2011). In this instance addiction can be defined as an:
Effects of e-mail addiction 
JSIT

14,1

86
[...] activity that takes over one's life [...] instead of being an enjoyable addition to their routine, it becomes a way to manage anxiety, stress, loneliness and depression that one feels or that which interferes with daily responsibilities (Maas, 2008).

The increase in self-diagnosed addiction however is in need of professional psychological diagnostics in order to add clinical justification to the level of addiction that email use causes.

The concept of addiction itself has been criticised both within and outside the mental health disciplines on a number of grounds: often it is used without an attempt to define it; it has moralistic connotations which are inappropriate to scientific inquiry; it represents a way of understanding people, behaviour and the mind that is incompatible with a scientific approach (Goodman, 1990). It is unsurprising therefore that over the last 20 years there have been much development of The Diagnostic and Statistical Manual of Mental Disorders (DSM) to serve as a guide for organising the components and definition of addiction (unrestricted by reference to a particular behaviour) (American Psychiatric Association, 2000).

Whilst the literature lacks psychologists' forthcomings in the area of addiction and email use, the repercussions of internet addiction have been widely raised, and merits for classification as a new psychiatric disorder in its own right (Young, 1996; Beard and Wolf, 2001; Yellowlees and Marks, 2005). Internet addiction, first indicated by Young, found that some on-line users were becoming addicted to the internet in much the same way that others become addicted to drugs or alcohol (Young, 1996). This clinical study based on similar questions to that used by DSM-IV (first published by American Psychiatric Association (1993)) for pathological gambling, used a questionnaire to test internet addiction. Respondents who answered "yes" to five or more, from eight adapted questions, were classified as addicted internet users or as normal internet users. Participants in this study either voluntarily participated using an online questionnaire or Young directly asked questions using telephone interviews (Young, 1996). Young hypothesised that meeting five out of eight rather than five out of ten criteria, from the original DSM-IV questionnaire, had a more rigorous cut off score to differentiate normal from addictive usage. Despite differences within the criteria analysis, Young's (1996) results suggest significant clinical addiction to the internet, with 396 dependent internet users and a control group of 100 non-dependent internet users being identified.

In a recent paper, Anderson (2011) interviewed Dr Tom Stafford from the University of Sheffield who believes, in a much different study to Young (1996) yet yielded similar results, that the fundamental learning mechanisms that drive gambling addicts can be associated with email users. Interestingly, and unlike any other literature on the topic, he claims that the "variable interval reinforcement schedule" is in play. Users sometimes check emails and there is nothing interesting, other times they might get something interesting or wonderful. Stafford argues that this is enough to make it difficult for users to resist checking email, even when they have only just looked. This opinion based article highlights a comparison between addiction and emails that would not usually be associated, although it provides little valid evidence to support the conclusions. Whilst the literature lacks the input of psychologists, independent coaches are coming forth with criteria to examine email use and levels of email addiction, such as Egan (2008). In addition, McKinney (2000) an academic coach, argues the basic premise is that our email addictions prevent conscious time management choices. Egan (2008) and McKinney (2000) raise very similar issues in behavioural characteristics 
of email addicts. However, both provide little statistical or quantitative research or testing in the subject area to provide support for their characterisation and labelling. This does not suggest their work is a mere fallacy, in contrast it takes the concept in a new direction, making for further research and assessment into email addiction.

The area of email addiction is growing in the research literature, but little classification has been formed. The use of Young's (1996) clinical addiction criteria and, Egan (2008) and McKinney's (2000) behavioural addiction criteria, as a method for assessing email addiction, takes the literature a step further in clarifying email addiction characteristics in the workplace. Comparison of the two criteria described in the preceding section led to the second hypothesis:

H2. Email addiction will exist in the workplace in line with literature findings of at least 15 per cent of respondents classified as email addicts. Criteria evaluation of clinical characteristics will occur consistent with behavioural characteristics, thus responses within Criteria 1 will occur consistent with Criteria 2.

\section{Method}

The study collected data from a large international car rental company with corporate-level head office and business-level branch operations in the UK. The company selected for the study was opportunistic, as one of the authors had experience of working there. There were two elements to this research. The first involved observing the effects of simulated email interruptions on seven employees by measuring the interrupt handling time, the interrupt recovery time, and the additional time required to complete the task given the number of interruptions. The employees were all of managerial status (i.e. branch manager or assistant manager). The day-to-day tasks of the managers involve communicating to customers and third parties (following up complaints, recovering monies, setting up new contacts) and communicating to staff and upper management (training, appraisals, meetings, audits). The seven participants ranged between the ages of 23-35 and they all had university degrees.

The second part of the study involved a questionnaire to capture addictive characteristics in employees' email communication behaviour. The questionnaire elicited "self-report" addiction criteria which are reported elsewhere (Young, 1996; Egan, 2008; McKinney, 2000). The questionnaire was disseminated to 100 employees. All participants frequently used email in the workplace, of which 74 completed the questionnaire anonymously. It was considered that examining email use can affect a person's emotional state (Ovsiankina, 1928; Mandler, 1964, 1984) therefore dimensions such as age, gender or race were omitted to avoid anxiety or hesitation for all parts of the study.

\subsection{Email interrupts experiment}

To determine the impact of email interrupts on the seven employees, they were asked to undertake their normal job of completing callbacks. A standard daily task completed by all company branches, where all employees are trained to the same standard. The callback process involves calling and speaking with the customer and/or garage, retrieve updates and process them onto two computer systems. Each item from the callback was calculated on a per person basis for consensus in scoring. Each experiment consisted of two callback tasks. Task 1 was to count and complete as many callbacks in 15 minutes, documenting results on the experiment handout. Task 2 was to complete

\section{Effects of e-mail addiction}


JSIT 14,1

88 the same number of callbacks as completed in Task 1, but this time the employee would be interrupted every five minutes by email that required an urgent reply. All email interrupts were 100 words in length, reflective of the workplace environment, and participants were made aware that each email was fictional and did not represent the company. Email interruptions were sent to participants until completion of Task 2. On completion of Task 2 all replies to the fictional emails were destroyed.

Each observation was conducted in a quiet, well-illuminated area of the office that contained two desks with computers on each. Participants sat out of sight of the observer, but the results of the study need to take into account the Hawthorne Effect as the behaviour of participants is likely to alter when observed (Swetnam, 2004).

\subsection{Email addict questionnaire}

It was considered that examining email use can affect a person's emotional state thus the reported effects of email are subject to some bias (Ovsiankina, 1928). The term "addiction" was perceived to be of a personal nature, therefore to avoid any further anxiety or hesitation, the questionnaire was titled "Evaluation of email usage questionnaire". For point of clarity, unlike previous research conducted, the questionnaire was not used to determine the frequency of email usage or any other conceptualisations. The purpose of this study was only to address the characteristics of email addiction. Each participant was administered with a 16 item check box of "yes-no" and "most often-least often" questions that most represented their typical work and email account behaviour.

Respondents were asked to indicate the extent to which they "[...] meet or exceed the criteria of an 'email addict". Email addiction was measured using two criteria, clinical characteristics (Criteria 1) and behavioural characteristics (Criteria 2). Clinical characteristics (Criteria 1) were based on the original study of DSM-IV for pathological gambling and later developed by Young to assess clinical addiction characteristics of internet use (Young, 1996). The Diagnostic Questionnaire (DQ) contained an eight-item classification list. Key terms of each question were replaced with "email", "email use" or "email account" as necessary. A nominal scale of "Yes" responses indicated addiction, and "No" responses indicated normal behaviour. Behavioural characteristics (Criteria 2) were based on email addiction symptoms from guidance councillors and life coaches, Egan (2008) and McKinney (2000), whom offer support for email addicted individuals (Egan, 2008; McKinney, 2000). The questions were chosen systematically by the common themes that were raised from both authors given first priority and then other symptoms were selected based on relevance in workplace environments. Items were measured by Likert scales. In order to encourage response rates, hard copies of the questionnaire were administered in green paper. Green paper has been found on average to aggregate an increase of 2 per cent when using questionnaires, whilst another reported a 9.1 per cent difference from white to green paper (Pucel et al., 1971).

\section{Results and discussion}

As mentioned in the methodology section the email interrupt study involved seven employees from a large international car rental company and involved two tasks. Task 1 was to complete as many callbacks in 15 minutes, and Task 2 was to complete the same number of callbacks with five minute email interruptions. 
$H 1$ assumed that stimulated five minute email interruptions will cause an interrupt handling time of around 1.5 minutes and a recovery time of around 64 seconds. The evidence from this study supported this hypothesis. Jackson et al.'s (2002) findings on interrupt recovery time calculated 64 seconds, the results in this study yield a similar average recovery time of 68 seconds. Subsequently, where Jackson et al. reports an interruption handling time of 90 seconds, these results indicate a slighter longer handling time of 116.5 seconds. On the basis of this study alone, it is difficult to be certain about the factors that contribute to the existence of the additional recovery time. As discussed earlier, time is lost dealing with an email interruption, and then further time is lost resuming previous activities. Research by Zull (2002) indicates that the brain needs time to empty the memory space to get back to the task at hand. However, the interference theory suggests the interruption causes a displacement of the memory trace, and in this case the interrupt recovery time is the brain seeking to find that memory trace again. The results of this research support the idea an additional recovery time exists, but it was not possible to definitively conclude on the brains functioning during this time.

The results from this study indicate that five minute email interruptions cause a task to take one-third longer than completing a task without email interruptions. The results show that, similarly to Solingen $e$ al. (1998) the negative aspects are more prominent than that of any positive interrupt effects on employees. During the study, there were signs that the interrupt disturbed concentration where a recovery time existed, and it caused task delay where additional handling time was present. Due to the number of participants it is difficult to be certain about the factors that contribute to the additional time, but it can be concluded that email interruptions cause a negative impact on employees. It is recommended employees adopt a "think before you check" and "think before you write" attitude in dealing with email to become aware of the issues surrounding email interruptions.

\subsection{Email addiction}

The email addiction questionnaire was administered to a large international car rental company, where a total of 74 employees responded. The questionnaire was split between two criteria, the first based on Young's DQ, and the second compiled from Egan and McKinney life coaches on email addiction (Young, 1996; Egan, 2008; McKinney, 2000).

The data from the questionnaire was analysed by first determining the general average of addiction characteristics, followed by frequency distributions to quantify the responses from both criteria. The questionnaire yielded two relations, either an email addict or not an email addict. The study adopted a similar evaluation criteria framework to that of Young's (1996) study. Therefore, any five questions responded to with a "Yes" in Criteria 1, or "Most Often" within Criteria 2, identifies the participant as an email addict. To distinguish the criteria an email addict is identified by both clinical and behavioural characteristics in isolation. Therefore, a participant could conceivably have normal subscale scores in the first criteria while still responding as an addict to a number of items within the other criteria. In addition, the data was analysed using a Pearson correlation co-efficient to examine any significance between clinical characteristics (Criteria 1) and behavioural characteristics (Criteria 2).

H2 assumed email addiction will exist in the workplace in line with literature findings of at least 15 per cent of respondents classified as email addicts. In addition, 
JSIT

14,1

90

Table I.

Characteristics of an email addict

the criteria evaluation of clinical characteristics will occur consistent with behavioural characteristics, thus responses within Criteria 1 will be consistent with Criteria 2 . The results of this study yield a very different view of the level of email addiction in the workplace, where the findings in this study indicate, based on clinical characteristics, only 12.2 per cent of users were email addicts, and 15 per cent of users were classified from the behavioural characteristics. AOL and Beta Research found evidence in 2007 showing 15 per cent of users and in a similar study in 2008, 48 per cent of users were email addicts (Begun, 2008). The participants in this survey only partially supported $H 2$, which may have been caused by the rigorous cut off score to differentiate normal from addictive use. An implication of this would be is if the criteria evaluation was marked lower, therefore four out of eight criteria indicated email addiction, the results would have doubled in the number of email addicted responses. Consequently, the correlation analysis shows no statistical significant relationship exists between Criteria 1 and Criteria 2. Taken together, these results suggest that whilst a relationship cannot be found to exist in this study, in future where a wider scale use of the questionnaire is implemented a relationship between the two criteria may be found. In light of these results, it is necessary to include both criteria in classifying email addiction. Table I shows the characteristics that can aid in classifying email addiction.

It can be concluded that both clinical and behavioural characteristics are necessary in classifying email addiction. If employees become aware of their behaviour, ultimately it will reduce habitual inclinations and bring greater effectiveness to email addiction.

\section{Conclusion and recommendations}

The results from this study highlight the many problems that are often associated with email use within organisations. In particular, this study explored email interruptions and email addiction in the workplace. The effect of an email interrupt becomes greater the more email is received and in this study five minute email interruptions caused an average handling time of 116.5 seconds, and recovery time of 68 seconds. Receiving email on an exponential rate becomes harder to manage and prioritise, so the interruptions lead to negative effects on employees. This was shown in the study findings where email interruptions caused a task to take a third longer, because it disturbed the employee's concentration and employees were generally seen to be less effective. Additionally, this study showed that the concept of email addiction exists in the workplace, where clinical characteristics classified at 12 per cent and behavioural characteristics classified at 15 per cent of email addicts. This research has shown the value in quantifying email addiction characteristics and measuring the level of addiction within an organisation. The correlation analysis has shown that there is no statistically

Clinical characteristics

Feeling preoccupied with emails

Feeling the need for more time to read emails Making repeated unsuccessful efforts to control, cut back or stop email use

Staying on your email account longer than originally intended
Behavioral characteristics

Opening email account first, before doing anything else

Leaving email programs open on computer screen between sessions Checking for email on an hourly basis (or less) 
significant relationship between clinical and behavioural characteristics. This has led to the need for both characteristics to be used in classifying email addiction.

Whilst a single study cannot provide a sound basis for the practice of email management, similar studies have suggested recommendations for employees and employers in the workplace to manage email interruptions and minimise email addiction. Burgess, Jackson and Edwards found evidence that educating employees through email training significantly reduced email interruptions and improved the way people write emails. It is recommended that employees "think before they write" and ask themselves:

Is this email necessary? If so, is the email easy to read and straight to the point? Does it tell what is expected of the recipient? Does it state what and when action is required? (Burgess et al., 2005).

It is vital for employers to convey this and could setup email training as part of their initial introduction or on-going personal development for all employees.

An understanding of addictive disorders has important connotations for treatment, in that optimal treatment would require that both positive and negative reinforcement processes be addressed (Goodman, 1990). An employee with addictive tendencies towards email could show a remarkable improvement by simply being aware of their problem behaviour or habitual inclination. For example, if an employee is consistently checking email on an hourly basis (or less) or leaves email open between sessions then they may find an email schedule useful to control their behaviour and manage their time more efficiently (McCorry, 2005). The steps to create an email schedule are shown in Table II. It is important to note these are suggested in light of the characteristics of email addiction as part of this study, further research is required to test these techniques and its application.

Although this research has shown both that email interruptions and addiction exists, it is acknowledged that there are limitations with the research. The study was

Schedule steps

Example

Choose a realistic number of times to check email per day

Set specific times throughout the day to manage email

Set duration of time to deal with email during

sessions

Specify email tasks to be complete during sessions

Tips and advice

Follow a regular and consistent schedule

Spend time to get used to the schedule to ensure it is realistic and email is manageable

During unscheduled time, turn off new email

alerts, or close inbox entirely to focus attention

If email correspondents are accustomed to

immediate responses then ensure they are aware

of the new schedule, i.e. send automated reply

explaining expected response time and alternative

contact details if message is urgent
Three times per day

First thing in the morning (9 am), after lunch $(1 \mathrm{pm})$, and end of day $(4.30 \mathrm{pm})$

Maximum 30 minutes per session

1st session - Read

2nd session - Read and Reply

3rd session - Send and File

\section{Effects of e-mail} addiction

91
Table II.

Steps to adopt an email schedule 
JSIT

14,1

92 constrained by the timeframes and availability of the participating organisation when administering the experiments. Ideally measuring an employee receiving email interruptions over a greater time period would achieve a more comprehensive understanding of how the initial impact of the interrupt is sustained, therefore the interrupt recovery time might be longer or shorter in a one-hour experiment. The most important limitation lies with the questionnaire. Although it was designed to capture email addiction characteristics within an organisational workplace, the evaluation criteria have not been used before. The scale used does provide a workable measure of email addiction, but further research is required to determine its construct validity and clinical utility. However, this research has shown that email interruptions do cause a negative impact on employees' time, and email can cause addictive behaviour in the workplace.

\section{References}

American Psychiatric Association (1993), DSM-IV Draft Criteria: 3/1/93, American Psychiatric Association, Washington, DC.

American Psychiatric Association (2000), Diagnostic and Statistical Manual of Mental Disorders: DSM-IV-TR, American Psychiatric Association, Arlington, TX.

Anderson, S.C. (2011), "Breaking the email compulsion", available at: www.guardian.co.uk/ technology/2008/aug/28/email.addiction (accessed 1 July).

Anthes, G. (2006), "E-mails 2nd act”, Computerworld, Vol. 40 No. 24, pp. 23-32.

Bawden, D. (2001), "Information and digital literacies: a review of concepts", Journal of Documentation, Vol. 57 No. 2, pp. 218-59.

Bawden, D., Holtham, C.W. and Courtney, N. (1999), "Perspectives on information overload", Aslib Proceedings, Vol. 51 No. 8, pp. 249-55.

Beard, K.W. and Wolf, E.M. (2001), "Modification in the proposed diagnostic criteria for internet addiction”, Cyber Psychology \& Behavior, Vol. 4 No. 3, pp. 377-83.

Begun, D.A. (2008), "Email addiction on the rise", available at: www.hothardware.com/News/ Email-Addiction-on-the-Rise/ (accessed 1 July 2011).

Brown, H. (2007), "View from the frontline: email stress", Health Information on the Internet, Vol. 1 No. 60, pp. 10-11.

Burgess, A., Jackson, T. and Edwards, J. (2005), "Email training significantly reduces email defects", International Journal of Information Management, Vol. 25 No. 1, pp. 71-83.

Czerwinski, M., Horvitz, E. and Wilhite, S. (2004), "A diary study of task switching and interruptions", Conference on Human Factors in Computing Systems, Proceedings of the SIGHI, Vol. 61 pp. 175-82.

DeMarco, T. and Lister, T. (1999), Peopleware: Productive Projects and Teams, 2nd ed., Dorset House Publishing Company, New York, NY.

Egan, M. (2008), "Egan email solutions: your productivity advantage", available at: www.eganemailsolutions.com/addiction.html\#If_you_think_youre_e-ddicted (accessed 1 July 2011).

Fallows, D. (2002), E-mail at Work, available at: www.twitter.comwww.pewinternet.com/ / media/Files/Reports/2002/PIP_Work_Email_Report.pdf.pdf (accessed 24 January 2012).

Goodman, A. (1990), “Addiction: definition and implications", British Journal of Addiction, Vol. 85 No. 11, pp. 1403-8. 
Hair, M., Renaud, K.V. and Ramsey, J. (2007), "The influence of self-esteem and locus of control on perceived email-related stress", Computers in Human Behavior, Vol. 23 No. 6, pp. 2791-803.

Hallowell, E.M. (2005), “Overloaded circuits: why smart people underperform”, Harvard Business Review, January, pp. 54-62.

Hiltz, S.R. and Turoff, M. (1985), "Structuring computer-mediated communication systems to avoid information overload", Communications of the ACM, Vol. 28 No. 7, pp. 680-9.

Jackson, T.W., Dawson, R.J. and Wilson, D. (2002), Evaluating the Effect of Email Interruptions Within the Workplace, paper presented at Conference on Empirical Assessment in Software Engineering, Keele, UK, April.

Jackson, T.W., Dawson, R.J. and Wilson, D. (2003), "Understanding email interaction increases organizational productivity", Communications of the ACM, Vol. 46 No. 8, pp. 80-4.

Kerr, E. and Hiltz, S. (1982), Computer-Mediated Communication Systems: Status and Evaluation, Academic Press, New York, NY.

Kieras, D.E., Meyer, D.E., Ballas, J.A. and Lauber, E.J. (2000), "Modern computational perspectives on executive mental processes and cognitive control: where to from here?", in Monsell, S. and Driver, J. (Eds), Control of Cognitive Processes Attention and Performance XVIII, MIT Press, London.

Lauber, E.J. (1995), "Executive control of task-switching operations", In Monsell, S. and Driver, J. (2000) Control of Cognitive Processes Attention and Performance XVIII, MIT Press, London.

Lichtenstein, S. and Swatman, P.M.C. (2003), Proceedings of the Seventh Pacific Asia Conference on Information Systems, Adelaide, 11 July, available at: www.dro.deakin.edu.au/eserv/ DU:30005160/lichtenstein-emailandknowledge-2003.pdf (accessed 20 January 2012).

McCorry, K.J. (2005), Organize Your Work - In No Time, Que Publishing, Indianapolis, IN.

McKinney, M. (2000), "Successful academic", available at: www.successfulacademic.com (accessed 1 July 2011).

Maas, N. (2008), "Internet addiction - does it really exist?", Wireless Design \& Development, Vol. 16 No. 12 , p. 6.

Mandler, G. (1964), "The interruption of behaviour", In Jackson T., Dawson R. and Wilson D. (2003), "Reducing the effect of email interruptions on employees", International Journal of Information Management, Vol. 23, No. 1, pp. 55-65.

Mandler, G. (1984), "Mind and emotion", In Jackson T., Dawson R. and Wilson D. (2003), "Reducing the effect of email interruptions on employees", International Journal of Information Management, Vol. 23, No. 1, pp. 55-65.

Mano, R.S. and Mesch, G.S. (2010), "E-mail characteristics, work performance and distress", Computers in Human Behavior, Vol. 26 No. 1, pp. 61-9.

Meyer, D.E., Evans, J.E., Lauber, E.J., Gmeindl, L., Rubenstein, J., Junck, L. and Koeppe, R.A. (1997), "Activation of brain mechanisms for executive mental processes in cognitive task switching”, Psychological Review, Vol. 104 No. 4, pp. 749-91.

O'Kane, P. and Hargie, O. (2007), "Intentional and unintentional consequences of substituting face-to-face interaction with email: an employee-based perspective", Interacting with Computers, Vol. 19 No. 1, pp. 20-31.

Ovsiankina, M. (1928), "Die wideraufnahme unterbrochener Handlungen", in Jackson T., Dawson R. and Wilson D. (2003) "Reducing the effect of email interruptions on employees", International Journal of Information Management, Vol. 23, No. 1, pp. 55-65.

\section{Effects of e-mail addiction}

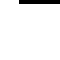


JSIT

14,1

94

Pucel, D., Nelson, H. and Wheeler, D. (1971), "Questionnaire follow-up returns as a function of incentives and responder characteristics", Vocational Guidance Quarterly, Vol. 19, pp. 188-93.

Rennie, J.D.M. (2000), "iFile: an application of machine learning to e-mail filtering”, Proceedings of KDD Workshop on Text Mining, Boston, 20-23 August, available at: www.citeseerx.ist. psu.edu/viewdoc/summary?doi=10.1.1.34.8826 (accessed 7 January 2010).

Rosen, C. (2008), "The myth of multitasking”, available at: www.thestar.com/living/article/ 452322 (accessed 1 July 2011).

Russell, P. (1979), “The brain book”, In Sousa, D.A. (2001), How the Brain Learns, Crown Press, London.

Solingen, R.I., Berghout, E. and Latun, F.V. (1998), "Interrupts: just a minute never is!", IEEE Software, Vol. 15 No. 5, pp. 97-103.

Sternberg, R.J. (2006), Cognitive Psychology, Wadsworth, New York, NY.

Swetnam, D. (2004), Writing Your Dissertation, How To Books Ltd, Oxford.

Tjaden, T. (2007), "Combating information overload", available at: www.slaw.ca/2007/06/26/ combating-information-overload/ (accessed 12 February 2009).

Whittaker, S. and Sidner, C. (1996), "Email overload: exploring personal information management of email", paper presented at the Conference on Human Factors in Computing Systems, Vancouver, 13 April.

Wojcik, E. (2005), "Full-time stress", Electronic Perspectives, Vol. 30 No. 4, pp. 50-5.

Yellowlees, P.M. and Marks, S. (2005), "Problematic internet use or internet addiction?", Computers in Human Behavior, Vol. 23 No. 3, pp. 1447-53.

Young, K.S. (1996), "Internet addiction: the emergence of a new clinical disorder", Cyber Psychology and Behaviour, Vol. 1 No. 3, pp. 237-44.

Zelikovich, D. (2011), "The negative effect of e-mails at work", Review of International Comparative Management, Vol. 12 No. 3, pp. 575-85.

Zull, J.E. (2002), The Art of Changing the Brain, Stylus Publishing, Virginia.

\section{Corresponding author}

Thomas W. Jackson can be contacted at: T.W.Jackson@lboro.ac.uk

To purchase reprints of this article please e-mail: reprints@emeraldinsight.com Or visit our web site for further details: www.emeraldinsight.com/reprints 